\title{
A note from the editors: enterovirus D68 epidemiology in France and Germany-food for thought
}

Eurosurveillance editorial team ${ }^{1}$

1. European Centre for Disease Prevention and Control (ECDC), Stockholm, Sweden

Correspondence: Eurosurveillance editorial team (eurosurveillance@ecdc.europa.eu)

Citation style for this article:

Eurosurveillance editorial team. A note from the editors: enterovirus D68 epidemiology in France and Germany-food for thought. Euro Surveill. 2016;21(19):pii=30229. DOI: http://dx.doi.org/10.2807/1560-7917.ES.2016.21.19.30229

Article published on 12 May 2016

Worldwide emergence of enterovirus (EV) D68 causing severe respiratory illness particularly in children, between 2008 and 2014, has been described in numerous articles. In 2014, EV-D68 gained particular attention when a large outbreak in children, associated with severe respiratory illness and possible neurological illness, occurred in the United States [1-3]. This event triggered a number of surveillance activities in various countries, some of them published in Eurosurveillance [4-8]. In our current issue we present investigations into the occurrence of EV-D68 in two European countries namely France and Germany.

The articles present data from patients hospitalised or visiting hospital emergency departments with respiratory symptoms. Schuffenecker et al. report on samples collected by eleven laboratories of the French EV surveillance network from eight of 22 Regions over six months in 2014 [9]. These eleven laboratories represent about one-third of the laboratories participating in the French EV network. Böttcher et al. analysed samples during two entire years, 2013 and 2014, at three large tertiary hospital laboratories in Germany [10]. These laboratories, situated mainly in the western part of the country, contribute ca $25 \%$ of the EV-positive samples in the nationwide RespVir surveillance [11].

Both reports are based on a considerable number of screened respiratory samples: 6,229 samples with 212 EV-D68 detections corresponding to 200 cases in France; 14,838 samples with 39 EV-D68-positive cases in Germany.

In line with the literature, the German analysis suggests seasonality of EV-D68 infections, with most cases occurring between September and November (weeks 36-48), and even though covering only six months, also the French analysis shows peaks in October (week 43) and November (week 48). Moreover, cases in both countries occurred mainly in children younger than five years, although French authors caution that a bias towards preferential sampling of children cannot be ruled out.

Clinical manifestation in children was characterised by asthma and bronchiolitis in France where ca $11 \%$ of the hospitalised paediatric cases and $14 \%$ of the hospitalised adult cases needed treatment in intensive care units, mostly due to severe respiratory symptoms. In Germany, clinical details were only available for a limited number of cases and in these pneumonia or obstructive bronchitis were the most common causes for hospitalisation. It should be noted that no neurological involvement was described over the two years for any of the EV-D68 cases diagnosed in the three German university hospital laboratories. In France however, four patients presented with neurological signs including one child who developed acute flaccid paralysis following EV-D68-associated pneumonia [6].

Sequence data show that the EV-D68 strains from all three German hospitals detected in 2013 and 2014 cluster together with worldwide circulating strains. The majority of sequences belonged to the B2 lineage; however, in both countries, clade A EV-D68 viruses were more frequent in adults than children. All German strains assigned to subclade $A 2$ were identified in adult patients and the authors demonstrated insertion of two amino acids at the C-terminus of VP1 of subclade A2 strains. However, there are at present no clear clinical implications associated with this change.

The two reports add to the body of evidence on EV-D68 epidemiology and circulating strains in Europe. They also illustrate the importance and usefulness of continuous molecular surveillance of EV in respiratory samples in combination with clinical information to detect changing trends and increasing severity of infections early. Last but not least they show that existing 
surveillance systems for respiratory infections can be adapted for such purposes.

\section{References}

1. Midgley CM, Jackson MA, Selvarangan R, Turabelidze G, Obringer E, Johnson D, et al. Severe respiratory illness associated with enterovirus D68 - Missouri and Illinois, 2014. MMWR Morb Mortal Wkly Rep. 2014;63(36):798-9.PMID: 25211545

2. Pastula DM, Aliabadi N, Haynes AK, Messacar K, Schreiner T, Maloney J, et al. , Centers for Disease Control and Prevention (CDC). Acute neurologic illness of unknown etiology in children - Colorado, August-September 2014.MMWR Morb Mortal Wkly Rep. 2014;63(40):901-2.PMID: 25299607

3. European Centre for Disease Prevention and Control (ECDC). Enterovirus 68 rapid risk assessment updated. Stockholm: ECDC 24; Nov. 2014. Available from: http://www.ecdc.europa. eu/en/press/news/_layouts/forms/New

4. Skowronski DM, Chambers C, Sabaiduc S, Murti M, Gustafson $\mathrm{R}$, Pollock S, et al. Systematic community- and hospital-based surveillance for enterovirus-D68 in three Canadian provinces, August to December 2014. Euro Surveill. 2015;20(43):30047. DOI: $10.2807 / 1560-7917 . E S .2015 \cdot 20.43 \cdot 30047$ PMID: 26804195

5. Midgley SE, Christiansen CB, Poulsen MW, Hansen $\mathrm{CH}$, Fischer TK. Emergence of enterovirus D68 in Denmark, June 2014 to February 2015. Euro Surveill. 2015;20(17):21105. DOI: 10.2807/1560-7917.ES2015.20.17.21105 PMID: 25955773

6. Lang M, Mirand A, Savy N, Henquell C, Maridet S,

Perignon $\mathrm{R}$, et al. Acute flaccid paralysis following enterovirus D68 associated pneumonia, France, 2014. Euro Surveill. 2014;19(44):20952. DOI: 10.2807/1560-7917. ES2014.19.44.20952 PMID: 25394254

7. Pfeiffer HC, Bragstad K, Skram MK, Dahl H, Knudsen PK, Chawla MS, et al. Two cases of acute severe flaccid myelitis associated with enterovirus D68 infection in children, Norway, autumn 2014. Euro Surveill. 2015;20(10):21062. DOI: 10.2807/1560-7917.ES2015.20.10.21062 PMID: 25788251

8. Meijer A, Benschop KS, Donker GA, van der Avoort HG . Continued seasonal circulation of enterovirus D68 in the Netherlands, 2011-2014. Euro Surveill. 2014;19(42):20935. DOI: 10.2807/1560-7917.ES2014.19.42.20935 PMID: 25358039

9. Schuffenecker I, Mirand A, Josset L, Henquell C, Hecquet D, Pilorgé $L$, et al. Epidemiological and clinical characteristics of patients infected with enterovirus D68, France, July to December 2014. Euro Surveill. 2016;21(19):30226. DOI: 10.2807/1560-7917.ES.2016.21.19.30226

10. Böttcher S, Prifert C, Weißbrich B, Adams O, Aldabbagh S, Eis-Hübinger AM, et al. Detection of enterovirus D68 in patients hospitalised in three tertiary university hospitals in Germany, 2013 to 2014. Euro Surveill. 2016;21(19):30227. DOI: 10.2807/1560-7917.ES.2016.21.19.30227

11. Respiratorisches Viren - Netzwerk (RespVir). German. [Accessed 20 May 2015]. Available from: http://rvdev.medicaldpc.com/

\section{License and copyright}

This is an open-access article distributed under the terms of the Creative Commons Attribution (CC BY 4.0) Licence. You may share and adapt the material, but must give appropriate credit to the source, provide a link to the licence, and indicate if changes were made.

This article is copyright of the European Centre for Disease Prevention and Control, 2016. 